\title{
Root Study: Why Is It behind Other Plant Studies?
}

\section{Moshe Silberbush}

Ben-Gurion University of the Negev, Jacob Blaustein Instutes for Desert Research-French Associates Institute for Agriculture and Biotechnology of Drylands, Sede-Boqer Campus, Midreshet-Ben-Gurion, Israel.

Email: silberbu@bgu.ac.il

Received October 21 $1^{\text {st }}$, 2012; revised November $25^{\text {th }}$, 2012; accepted December $3^{\text {rd }}, 2012$

\begin{abstract}
Until the 1980s, root studies were typically conducted in nutrient solution, because of the technical difficulties of studying roots in their natural environment, soil. Recent innovations and the realization that there are gaps between the expected and actual performance of plant root systems have emphasized the need for more realistic solutions. This review analyzes the study of plant roots in view of developments in soil science, microbiology, botany and plant physiology, and recently the introduction of molecular biology and computerized imaging.
\end{abstract}

Keywords: Root Architecture; Nutrient Uptake Modeling; Rhizosphere; Soil and Root Relationships

\section{Introduction}

\subsection{General}

Waisel et al. [1] added to the main title of their book, "Plant Roots", a sub-title: "The Hidden Half”. This addition expressed their view that plant roots are poorly understood: while the aboveground parts of plants were studied thoroughly for several centuries [2], studies of roots grown in soil are still well behind. This review summarizes and provides perspectives on the present state of root studies.

\subsection{Evolution and Development of Plant Roots}

Life on Earth was apparently initiated in water where heterotrophic, and than autotrophic life forms were evolved [2]. Following the logic of Dawkins [3], the struggle for self-reproduction of genes, and further of genotypes and populations, forced them to explore new habitats to expand their presence in space and survival in time. Such expansion had to be associated with adaptations to new external conditions, and was involved with both physiological and morphological adaptations. As a result, the evolution of different organs occurred, involving competition with one another for resources while using the products of one another in order to function better as a whole. Organs and tissues evolved, specialized in different functions, like absorbing light by broad and thin leaves to produce sugars and other photosynthetic products, translocation by phloem and xylem vessels, storage capacities in tissues and organs for times of need, reproduction organs etc., all in the same organism, with control and coordination between the different sources and sinks, to achieve the best mutual performance.

As long as life occurred in water, the exchange of gases and solutes via all surfaces was fast and sufficient. The need to develop tissues and organs that are specialized in absorbance and release of those substances was not crucial for the very existence of organisms. At those early evolutionary stages, roots basically served as means to physically anchor the plant structure. The primary functions of roots of terrestrial plants, water and nutrient acquisition, were not essential under such conditions. Although some aquatic plants do have roots, these may relics of previous adaptations to life outside water $[4,5]$ : Members of the floating angiosperm Lemna spp. have roots with xylem, but without vessels. Some aquatic plants have roots with suberized Casparian strips, indicating a different genetic background of terrestrial plants that re-adapted to live in water.

The ability of plants to live on land required major revolutionary changes: to start with, plants had to develop means to avoid water losses out of their tissues. Means like cuticle covers on the broad leaves, with stomata to enable gas exchange while controlling water losses are evident in all terrestrial plants, with advanced sophistication in those plants adapted to live and survive in extremely dry and arid habitats. Looking at the global distribution of plant families and species, the mosses, with non-sophisticated stomata, are abundant in cold and humid climates, while those of arid and hot climates possess thick cuticles, hairy leaves with stomata protected in depressions covered by hairs, succulent leaves and other water storage means. Many species and families of this group use the more water efficient C-4 rather 
than C-3 photosynthesis, or CAM (Crassulacean Acid Metabolism) photosynthesis to minimize exposure to drought $[6,7]$. Phenology adapted to the change in seasons, to match the active phases to periods when liquid water is available while avoiding freezing or dry periods. As a rule, plants that live in water are more universally dispersed than dry-land species: Common Reed, Phragmites australis, and Water Lily, Nymphaea sp., continuously invade highly diverse wetlands throughout the world [8,9].

Provision of water and nutrients to plants under terrestrial conditions depends on resources supplied by the soil (except epiphytes, that live detached from the soil, but restricted to humid conditions). The organ that evolved to provide this essential link with the soil is the root. Unlike life in water, roots of terrestrial plants had to adapt to a wide range of soil hydration levels. Less is known about the drought adaptations of roots than of shoots, simply because shoots are more accessible. That is, although early studies already pointed out inherent gaps in our knowledge on the root-soil system: As soil dries, its volume must be reduced. Also, there might occur shrinkage of roots when exposed to a drying soil [10]. Based on these facts, Taylor and Klepper [11] concluded that, under drying soil conditions, soil water flow to the root surface should drop with soil moisture decrease, since a gap between the soil and the root surface should develop due to both root and soil shrinkage [12]. In fact, the change in water flow to roots grown in drying soils does not indicate the occurrence of such a gap (often referred to as the Klepper-Taylor paradox). Furthermore, measurements made by P.S. Nobel on water uptake by desert plants, resulted in a relatively small drop in water flux to roots under drying soil conditions, although the roots shrank under water deficit $[13,14]$. Also, relatively little water was lost from the root as a flow-back to the drying soil, as water potential gradient apparently should cause. They also showed that certain desert plants can fill the gap formed due to the root shrinkage by root gel-like exudates, so a continuation of the soil-root system was maintained, as was supported by McCully [15]. Recently, Carminati et al., [16] used neutron radiography to measure water content in the soil at the very proximity of the root surface. This study indicated that changes in the soil properties around roots, apparently due to exuded mucilage, that affected the hydraulic properties of the soil on drying or wetting processes by changing the soil water retention characteristics differently on drying or wetting (and accordingly its hydraulic conductivity), a phenomenon known as hysteresis (i.e., affected by the change direction). These changes moderated the drop of moisture around the root in a drying soil. It took about 40 years to cover the gap in our understanding of how plant roots are adapted to live in a drying soil.

\section{Studies of Root Function}

Studies of root function followed studies of root anatomy and morphology, primarily employing plants grown in nutrient solutions [17]. Studies of roots grown in soil were generally crude and indirect by comparison [18]. The concern arises that roots grown out of the soil behave and function abnormally.

\subsection{The Single-Root Models}

An example to the above dilemma is presented in the widely used single-root Barber-Cushman [19] model ${ }^{1}$. The model treats the system as two concentric cylinders, where the inner is the root (with constant radius, and no extensions like branching, lateral roots, root hairs or mycorrhizal hypha), whose center is the spatial reference to the soil-root system, with radial orientation [20]. The soil, (assumed homogeneous and isomorphic, with constant moisture content) forms an external cylinder around the root, also with a constant radius. Movement of water and solutes in the soil system is radial to the root only, by mass-flow and diffusion, following Nye and Marriott [21]. Water flow, controlled by the transpiration demand (assumed constant with time), obeys the radial geometry of the system and mass conservation. Nutrient uptake rate is a function of concentration of the ion in question in the soil solution at the root surface, assuming that uptake occurs from a solution only, without interaction with other solutes. Updates to this basic feature by other authors include moving boundaries, either the inner (root radius) or external (the rhizosphere extent) to account for root growth with time and consequent increase in root density, and changes of hierarchy in a root system².

\subsection{Water and Ion Radial Flow to Roots}

The combined flow of water and ions in the soil by mass-flow (convection) and diffusion was studied by soil scientists since the 1940s. A major contribution to these studies was provided by P. H. Nye and co-workers [22], with a special treatment of the radial flow to roots [21]. Uptake kinetics by plant roots was studied in solutions [17]. To put all these components together, Barber and Cushman [19] assume that the flow rate from the soil (that obeys the rules of flow in porous media) and the flux into the root surfaces (a function of the nutrient concentration) should match to maintain mass conservation. To do this, the model assumes the occurrence of a dummy compartment between the soil and the root sur-

\footnotetext{
${ }^{1}$ Although there are several other similar models, they all share the same concepts.

${ }^{2}$ In fact, Cushman provided solutions to two cases: one is the constant outer boundary as discussed. The other is a boundary that extends with the depletion of ion's concentration in the soil due to uptake by the root, as a function of the diffusion coefficient and time.
} 
face (the interface compartment), where the two flows serve as input (from the soil) and output (into the root surface). Since Uptake rate initiates the flow from the soil into that compartment, it should be merely a mathematical problem; it appeared that this was a critical point, not simple at all:

As the two mechanisms are of different nature, this solution works in relatively low concentrations, where the uptake mechanism is governed by the concentration [17] while the major flow in the soil is due to diffusion. This assumption was needed, as the flow in the soil changes linearly with time and distance (from one point to the other, by Fick's law and continuity), but influx to the root as a function of concentration has the nature of a saturation function (although with more advanced mathematical techniques, modern models overcame this limitation). Cushman's original model was, therefore, limited to low concentrations, where linearization of the flow was an essential assumption, as specified by the title of his paper [20]. Without this condition, the solution would be unstable. The justification to this condition was that the concentration in the soil solution at the root should drop with time anyway, due to uptake by the root, as no nutrient would be added to the soil system (depletion only).

\subsection{The External Boundary}

Soil conditions at the external boundary, which stands for the rhizosphere radial extension, also need a solution. In the Barber-Cushman model, the extent of the soil compartment is constant, and no solute flow is allowed through that boundary (water flow is not limited). This means that, in a root system that grows with time, the explored soil volume should extend too with time, which is not always the case. Also, the addition of nutrients by fertilization is a common agricultural practice. As a result, the model works reasonably well in plants grown in pots, where the root system was rather uniformly distributed, but not so well when applied to field conditions [23]. Models that accounted for changes in root density did not entirely solve the low predictability of those of constant borders [24].

\subsection{One Nutrient at a Time?}

No interactions between the nutrients/ions were allowed: each nutrient was treated as the only substance absorbed by the root. This condition never occurs in reality, since plants take up a mixture of nutrients, and the soil solution is basically a variety of solutes in water. It is abnormal therefore (even impossible) for a root to grow in a single ionic environment. Ions are always accompanied by their contra-species, to maintain electro-neutrality. Plants fed with $\mathrm{NO}_{3}^{-}-\mathrm{N}$ cause the $\mathrm{pH}$ of growth medium to rise, as plants require nitrogen in larger molar quantities than the other mineral nutrients; the opposite would happen when the dominant $\mathrm{N}$ form is $\mathrm{NH}_{4}^{+}$[25]. Roots must be supplied with calcium to grow and function normally (the Viets' effect', after Viets [26]. It appeared that one of the fundamental functions of $\mathrm{Ca}^{2+}$, in addition to others, is to bind the plant cell-wall PGA (PolyGalacturonic Acid) units, which enables cell-wall extension and consequent root growth $[27,28]$. Balance between $\mathrm{Ca}$ and $\mathrm{Al}, \mathrm{Na}$ and $\mathrm{K}$ concentrations affects root growth and development. These are examples of common behavior of the soil-root system that is not accounted by the Barber-Cushman model, since it cannot handle uptake of more than one nutrient at a time.

\section{Root and Soil Relations}

\subsection{The Soil-Root Interface}

The way the Barber-Cushman model handles the flow from the bulk soil to the root surface is also a question: Roots are surrounded by their exudates, originated either by the disintegration of the root cap during their penetration into the soil, and by exudates that are actively released by the vital root surfaces [15]. These exudates change the chemical and microbiological nature of the soil at the root surface, but also the physical properties of water movement and retention characteristics of the rhizosphere [29]. At least some of the discrepancies between nutrient uptake simulated by the single-root models and those actually observed in plants are believed to be due to this fault, as in the case of P [23] and Mn [30].

\subsection{Roots as Systems}

Most the above studies were carried out assuming that the local soil-root interaction may be integrated in the whole soil-root system, and this will provide the "true" behavior and functioning of the entire system. The rationale behind the single-root models was that roots within the system do not affect each other, so the soilroot system may be lumped into a concentric set of cylinders. This view appears to be inaccurate and even misleading: roots of different parts of the system do affect each other. Even without accounting for biological or chemical interaction between the root and the soil, but with a series of simple assumptions of branching, Roose and Fowler [31] showed that the calculated P uptake was substantially higher than what was predicted by the single-root Barber-Cushman model. They also showed that the change was due to a more intensive foraging of the soil exposed to the roots. The solution lies therefore in using the realistic structure of the root system, with its systematic branching and different root hierarchies. It appeared that only the inability to cope with the complex structure and the low power of computers at the time 
apparently caused this inappropriate handling of the system. As a result, the soil-root system is not regarded anymore in the recent models as a "homogeneous-isotropic growth medium, where roots are randomly dispersed”, but as a root system controlled by its genes, with a wide capability to react to environmental (i.e., physical, chemical or biological) changes [32]. The result is the introduction of studies on root architecture as a tool to quantify uptake by plants. The link between the genotype and the structure and function of the root system is of major topics in modern plant studies. Advances in the molecular studies also contributed to this line of studies $[33,34]$. Yet, the expression of the genotype in response to environmental conditions is still behind. Also, shifting from one growth phase to another (like vegetative and reproductive) is still not satisfactorily accounted for, also changes between seasons, which are inherent characteristics of perennial plant growth.

\subsection{Root Interactions with Their Biological Environment}

Interactions of roots with their biological environment, both micro- and macro-organisms, was a subject to many studies. It was demonstrated by several studies that the root and its bacterial associates act as a functional unit: The roots exude substances on which the bacteria are fed [35]. They, on their part, release and decompose materials that otherwise are unavailable to the root. Yet, the study of such a system is inherently problematic: Microbiologists have to isolate the target bacteria and grow them under lab conditions, since growing such a culture under natural conditions is impossible using their methodologies [36,37]: Isolation would cause interferences, since the system by nature is located at the soil-root interface. A similar obstacle lies in studying root-mycorrhizal relationships, although many studies were obtained from intact tree roots exposed and treated in situ [38]. The role of mycorrhizal fungi in the soil-plant interrelationships is far from being clear, and still needs further studies [39].

\section{Conclusion}

Root study, which was way behind the other plant sciences, was changed during the second half of the 20th century, but has accelerated since that time [40,41]. It was not only the technological innovations that enabled this trend; it is mainly the notion that there is a missing gap in plant studies, and in life sciences in general, that is incomplete without this link. The evolution of plant adaptation to live on earth is incomplete without our understanding of how plants adapted to live on earth, out of water. Traditionally, scientists ignored this lack of knowledge by using bypasses: growing plants in solutions, in aeropoics, and assuming that the equation [soil sciences without plant roots + plants grown without soil] will provide a genuine [sum of the complete system of plants grown in soil]. Eventually, reality showed that this is not the case, but merely an illusion. It is time to get into our mind that our methodologies were incomplete and to develop methods of studying plants grown in their natural growth medium. How to do it-that will be the challenge of our generation, and of the generations to come.

\section{Acknowledgements}

Dedicated to the memory of Yoav Waisel, a great teacher with outstanding scientific and human views.

\section{REFERENCES}

[1] Y. Waisel, A. Eshel and U. Kafkafi, "Plant Roots-The Hidden Half,” 3rd Edition, Marcel Dekker Inc., New York, 2002.

[2] H. Hartman, "Photosynthesis and the Origin of Life," Origins of Life and Evolution of Biospheres, Vol. 28, No. 4-6, 1998, pp. 515-521. http://www.ncbi.nlm.nih.gov/pubmed/11536891

[3] R. Dawkins, “The Selfish Gene,” Oxford University Press, Oxford, 1976.

[4] A. D. Barnabas, "Casparian Band-Like Structures in the Root Hypodermis of Some Aquatic Angiosperms," Aquatic Botany, Vol. 55, No. 3, 1996, pp. 217-225. doi:10.1016/S0304-3770(96)01072-8

[5] J. A Raven and D. Edwards, "Roots: Evolutionary Origins and Biogeochemical Significance," Journal of Experimental Botany, Vol. 52, Special Issue, 2001, pp. 381401. doi:10.1093/jexbot/52.suppl_1.381

[6] A. Läuchli and U. Lüttge, "Salinity: Environment-PlantsMolecules,” Kluwer, Dordrecht, 2002.

[7] A. Shomerilan, A. Nissenbaum and Y. Waisel, "Photosynthetic Pathways and the Ecological Distribution of the Chenopodiaceae in Israel,” Oecologia, Vol. 48, No. 2, 1981, pp. 244-248. doi:10.1007/BF00347970

[8] R. Chambers, L. A. Meyerson and K. Saltonstall, "Expansion of Phragmites australis into Tidal Wetlands of North America,” Aquatic Botany, Vol. 64, No. 2, 1999, pp. 261273. doi:10.1016/S0304-3770(99)00055-8

[9] T. Borsch, C. Loehne and J. Wiersema, "Phylogeny and Evolutionary Patterns in Nymphaeales: Integrating Genes, Genomes and Morphology,” 17th International Botanical Congress, Vienna, 17-23 July 2005, pp. 1052-1081.

[10] M. G. Huck, B. Klepper and H. M. Taylor, "Diurnal Variations in Root Diameter,” Plant Physiology, Vol. 45, No. 4, 1970, pp. 529-530. doi:10.1104/pp.45.4.529

[11] H. M. Taylor and B. Klepper, "Water Uptake by Cotton Root Systems: An Examination of Assumptions in the Single Root Model,” Soil Science, Vol. 120, No. 1, 1975, pp. 57-67. doi:10.1097/00010694-197507000-00009

[12] E. A. Waraich, R. Ahmad, Saifullah, M. Y. Ashraf and Ehsanullah , "Role of Mineral Nutrition in Alleviation of 
Drought Stress in Plants," Australian Journal of Crop Science, Vol. 5, No. 6, 2011, pp. 764-777.

[13] P. S. Nobel and M. Cui, "Hydraulic Conductances of the Soil, the Root-Soil Air Gap, and the Root: Changes for Desert Succulents in Drying Soil," Journal of Experimental Botany, Vol. 43, No. 248, 1992, pp. 319-326. doi:10.1093/jxb/43.3.319

[14] G. B. North and P. S. Nobel, "Drought Induced Changes in Soil Contact and Hydraulic Conductivity for Roots of Opuntia ficus indica with and without Rhizosheaths," Plant and Soil, Vol. 191, No. 2, 1997, pp. 249-258. doi:10.1023/A:1004213728734

[15] M. E. McCully, "Roots in Soil: Unearthing the Complexities of Roots and Their Rhizospheres,” In: R. L. Jones, Ed., Annual Review of Plant Physiology and Plant Molecular Biology, Vol. 50, Annual Reviews Inc., Palo Alto, 1999, pp. 695-718.

[16] A. Carminati, A. B. Moradi, D. Vetterlein, P. Vontobel, E. Lehmann, U. Weller, H. J. Vogel and S. E. Oswald, "Dynamics of Soil Water Content in the Rhizosphere," Plant and Soil, Vol. 332, No. 1-2, 2010, pp. 163-176. doi:10.1007/s11104-010-0283-8

[17] E. Epstein and A. J. Bloom, "Mineral Nutrition of Plants: Principles and Prospectives," 2nd Edition, Sinauer Associates, Inc., Sunderland, 2005.

[18] A. Jungk and N. Claassen, “Availability of Phosphate and Potassium as the Result of Interactions between Root and Soil in the Rhizosphere," Zeitschrift für Pflanzenernahrung und Bodenkunde, Vol. 149, No. 4, 1986, pp. 411427. doi:10.1002/jpln.19861490406

[19] S. A. Barber and J. H. Cushman, "Nitrogen Uptake Model for Agronomic Crops,” In: I. R. Iskandar, Ed., Modeling Wastewater Renovation-Land Treatment, WileyInterscience, New York, 1981, pp. 382-409.

[20] J. H. Cushman, “An Analytical Solution to Solute Transport near Root Surfaces for Low Initial Concentration. I. Equations Development," Soil Science Society of America Journal, Vol. 43, No. 6, 1979, pp. 1087-1090.

[21] P. H. Nye and F. H. C. Marriott, “A Theoretical Study of the Distribution of Substances around Roots Resulting from Simultaneous Diffusion and Mass Flow," Plant and Soil, Vol. 30, No. 3, 1969, pp. 459-472. doi:10.1007/BF01881971

[22] P. B. Tinker and P. H. Nye, "Solute Movement in the Rhizosphere,” 2nd Edition, Oxford University Press, Oxford, 2000.

[23] M. Silberbush and S. A. Barber, "Root Growth, Nutrient Uptake and Yield of Soybean Cultivars Grown in the Field," Communications in Soil Science and Plant Analysis, Vol. 16, No. 1, 1984, pp. 119-127. doi:10.1080/00103628509367591

[24] P. J. Smethurst and N. B. Comerford, "Simulating Nutrient Uptake by Single or Competing and Contrasting Root Systems," Soil Science Society of America Journal, Vol. 57, No. 5, 1993, pp. 1361-1367. doi:10.2136/sssaj1993.03615995005700050033x

[25] R. Ganmore-Neumann and U. Kafkafi, "Root Temperature and Percentage $\mathrm{NO}_{3}{ }^{-} / \mathrm{NH}_{4}{ }^{+}$Effect on Tomato Devel- opment. II. Nutrients Composition of Tomato Plants," Agronomy Journal, Vol. 72, No. 5, 1980, pp. 762-766. doi:10.2134/agronj1980.00021962007200050017x

[26] F. G. Viets, "Calcium and Other Polyvalent Cations as Accelerators of Ion Accumulation by Excised Barley Roots,” Plant Physiology, Vol. 19, 1944, pp. 466-480. doi:10.1104/pp.19.3.466

[27] J. Messiaen, N. D. Read, P. Van Cutsem and A. J. Trewavas, "Cell Wall Oligogalacturonides Increase Cytosolic Free Calcium in Carrot Protoplasts,” Journal of Cell Sciences, Vol. 104, No. 2, 1993, pp. 365-371.

[28] U. Yermiyahu, S. Nir, G. Ben-Hayyim, U. Kafkafi and T. B. Kinraide, "Root Elongation in Saline Solution Related to Calcium Binding to Root Cell Plasma Membranes," Plant and Soil, Vol. 191, No. 1, 1997, pp. 67-76. doi:10.1023/A:1004241506347

[29] S. Czarnes, A. R. Dexter and F. Bartoli, "Wetting and Drying Cycles in the Maize Rhizosphere under Controlled Conditions. Mechanics of the Root-Adhering," Plant and Soil, Vol. 221, No. 2, 2000, pp. 253-271. doi:10.1023/A:1004747323220

[30] U. S. Sadana and N. Claassen, "Manganese Dynamics in the Rhizosphere and Mn Uptake by Different Crops Evaluated by a Mechanistic Model," Plant and Soil, Vol. 218, No. 1-2, 2000, pp. 233-238. doi:10.1023/A:1014964107614

[31] T. Roose and A. C. Fowler, "A Mathematical Model for Water and Nutrient Uptake by Plant Root Systems," Journal of Theoretical Biology, Vol. 228, No. 2, 2004, pp. 173-184. doi:10.1016/j.jtbi.2003.12.013

[32] V. M. Dunbabin, S. McDermott and A. G. Bengough, "Upscaling from Rhizosphere to Whole Root System: Modelling the Effects of Phospholipid Surfactants on Water and Nutrient Uptake,” Plant and Soil, Vol. 283, No. 1-2, 2006, pp. 57-72. doi:10.1007/s11104-005-0866-y

[33] J. P. Lynch, "Roots of the Second Green Revolution (a Review)," Australian Journal of Botany, Vol. 55, No. 5, 2007, pp. 493-512. doi:10.1071/BT06118

[34] R. E. Haling, R. J. Simpson, R. A. Culvenor, H. Lambers and A. E. Richardson, "Field Application of a DNABased Assay to the Measurement of Roots of Perennial Grasses," Plant and Soil, Vol. 358, No. 1-2, 2012, pp. 183-199. doi:10.1007/s11104-012-1405-2

[35] D. V. Badri and J. M. Vivanco, "Regulation and Function of Root Exudates," Plant Cell and Environment, Vol. 32, No. 6, 2009, pp. 666-681. doi:10.1111/j.1365-3040.2009.01926.x

[36] P. J. Gregory, "Roots, Rhizosphere and Soil: The Route to a Better Understanding of Soil Science?” European Journal of Soil Science, Vol. 57, No. 1, 2006, pp. 2-12. doi:10.1111/j.1365-2389.2005.00778.x

[37] P. Marschner, D. Crowley and Z. Rengel, "Rhizosphere Interactions between Microorganisms and Plants Govern Iron and Phosphorus Acquisition along the Root AxisModel and Research Methods," Soil Biology and Biochemistry, Vol. 43, No. 5, 2011, pp. 883-894. doi:10.1016/j.soilbio.2011.01.005

[38] M. S. Lucash, D. M. Eissenstat, J. D. Joslin, K. J. McFarlane and R. D. Yanai, "Estimating Nutrient Uptake by 
Mature Tree Roots under Field Conditions: Challenges and Opportunities,” Trees Structure and Function, Vol. 21, No. 6, 2007, pp. 593-603. doi:10.1007/s00468-007-0160-0

[39] H. Kahiluoto, E. Ketoja and M. Vestberg, "Plant-Available P Supply Is Not the Main Factor Determining the Benefit from Arbuscular Mycorrhiza to Crop P Nutrition and Growth in Contrasting Cropping Systems," Plant and Soil, Vol. 350, No. 1-2, 2012, pp. 85-98. doi:10.1007/s11104-011-0884-X

[40] S. R. Tracy, C. R. Black, J. A. Roberts and S. J. Mooney, "Soil Compaction: A Review of Past and Present Tech- niques for Investigating Effects on Root Growth,” Journal of the Science of Food and Agriculture, Vol. 91, No. 9, 2011, pp. 1528-1537. doi:10.1002/jsfa.4424

[41] I. De Smet, P. J. White, A. G. Bengough, L. Dupuy, B. Parizot, I. Casimiro, R. Heidstra, M. Laskowski, M. Lepetit, F. Hochholdinger, X. Draye, H. M. Zhang, M. R. Broadley, B. Peret, J. P. Hammond, H. Fukaki, S. Mooney, J. P. Lynch, P. Nacry, U. Schurr, L. Laplaze, P. Benfey, T. Beeckman and M. Bennett, "Analyzing Lateral Root Development: How to Move Forward?” Plant Cell, Vol. 24, No. 1, 2012, pp. 15-20. doi:10.1105/tpc.111.094292 